\title{
Validation of the Frenchay activity index on stroke victims
}

\author{
Validação do índice de atividades de Frenchay em indivíduos após AVC \\ Maiana Monteiro, , Iara Maso ${ }^{2,3}$, Adriana Campos Sasaki 1,2, Nestor Barreto-Neto ${ }^{1}$, Jamary Oliveira-Filho', \\ Elen Beatriz Pinto ${ }^{1,2}$
}

\begin{abstract}
Purpose: To evaluate the inter-rater reliability and predictive validity of the Frenchay Activities Index (FAI) in patients after stroke. Methods: One hundred sixty-one patients were selected for consecutive application of the FAI and National Institutes of Health Stroke Scale (NIHSS). Spearman's test was used for correlation between different scales. The FAI and NIHSS association was evaluated using ordinal logistic regression. Additionally, 36 patients underwent FAl rating on the same day by two independent evaluators. Results: A negative correlation between the FAl and the NIHSS scores ( $p=0.017 r=-0.22$ ) was found. Adjusting all variables with possible association with the NIHSS, ordinal logistic regression showed that the FAl had a significant association with NIHSS scores (OR 0.93, 95\% Cl 0.87 to 0.99, p: 0.033). The inter-rater agreement was considered good, $k=0.66$ ( 0.54 to 0.78 ), $p<0.001$. Conclusions: The FAl is a valid and useful method to assess instrumental activities before acute stroke in a Brazilian population.
\end{abstract}

Keywords: stroke; activities of daily living; validation studies.

\section{RESUMO}

Objetivo: Avaliar a confiabilidade inter-examinador e a validade preditiva do Índice de Atividades de Frenchay (FAl) em pacientes após acidente vascular cerebral. Métodos: 161 pacientes foram selecionados para aplicação consecutiva da FAI e NIH Stroke Scale (NIHSS). $O$ teste de Spearman foi utilizado para correlação entre as diferentes escalas. A associação FAl e NIHSS foi avaliada por meio de regressão logística ordinal. Adicionalmente, 36 pacientes foram submetidos à aplicação do FAl por dois avaliadores independentes, no mesmo dia. Resultados: Foi encontrada uma correlação negativa entre o FAl e o NIHSS ( $r=-0,22 ; p=0,017$ ). Ajustando todas as variáveis com possível associação com NIHSS, a regressão logística ordinal demonstrou que o FAl tem associação significativa com o NIHSS (OR 0,93, 95\% Cl 0,87-0,99, p: 0,033). A concordância entre avaliadores foi considerada boa, $k=0,66$ (0,54-0,78), p < 0,001. Conclusões: FAl é um método válido e útil para avaliar atividades instrumentais antes de AVC agudo em uma população brasileira.

Palavras-chave: acidente vascular cerebral; atividades cotidianas; estudo de validação.

Stroke, besides being an important cause of death, is the leading cause of severe disability and dependence, affecting activities of daily living (ADL) ${ }^{1}$. According to a study conducted in Latin America, the proportion of stroke survivors requiring care varies between $20 \%$ and $39 \%$. A significant proportion of these survivors have a moderate or severe disability and require the assistance of a caregiver, increased family support and resource utilization from the health system and other social institutions ${ }^{2}$.

In recent years, different studies have evaluated the functional prognosis through determinants prior to disease or from the acute/subacute stroke phases ${ }^{3,4}$. Activities of the individual prior to stroke are identified as a factor that interferes with functional outcome after stroke. According to some authors, a previously active lifestyle, including physical and cognitive activities, can generate a protective effect after stroke ${ }^{5,6}$.

Among the pre-morbid activities that can be evaluated are the ADL, which are basic activities carried out by the individual, and instrumental activities of daily living (IADL), which are more elaborate and thus require higher cognition and interaction with the environment ${ }^{7}$. The Frenchay Activity Index (FAI) was developed to objectively assess instrumental

\footnotetext{
'Universidade Federal da Bahia, Ambulatório de Doenças Cerebrovasculares, Salvador BA, Brasil;

${ }^{2}$ Escola Bahiana de Medicina e Saúde Pública, Salvador BA, Brasil;

${ }^{3}$ Hospital Geral Roberto Santos, Unidade de AVC, Salvador BA, Brasil.

Study conducted at the Hospital Geral Roberto Santos, Salvador, Brazil.

Correspondence: Elen Beatriz Pinto; Escola Bahiana de Medicina e Saúde Pública (EBMSP); Avenida D. João VI, 275; 40290-000 Salvador BA, Brasil; Email:elen.neuro@gmail.com

Conflict of interest: There is no conflict of interest to declare.
}

Received 25 November 2014; Received in final form 07 October 2016; Accepted 21 November 2016. 
activities performed by the patient in the recent past. Much of the FAI score is based on the frequency with which activities are performed. This evaluation focuses on domestic activities, work/leisure and outdoor activities. It is described as a fast, easy-to-use, reliable and sensitive instrument to measure functionality before and after the stroke, but it is not yet validated in Brazil ${ }^{8,9,10}$. Moreover, an association between the FAI and stroke severity on admission, has not been documented.

The aim of this study is to show the reproducibility and predictive validity of the FAI in patients after stroke.

\section{METHODS}

This is a study directed to the validation of the Frenchay Activity Index in a sample of the Brazilian population, with baseline data from a cohort. The sample comprised patients admitted to a public hospital in the city of Salvador, Brazil, with a diagnosis of stroke, who were functionally independent prior to stroke (individuals with a modified Barthel Index equal to 50) and age above 18 years. Stroke was defined as an acute focal neurological deficit, with a duration greater than 24 hours $^{11}$. The diagnosis of stroke was confirmed by CT and/or MRI, and included ischemic or hemorrhagic stroke. Exclusion criteria included: individuals who had difficulties understanding the evaluation or had no companion to answer questions; patients who were diagnosed with other neurological or orthopedic pathologies associated with functional impairment; and those who refused to participate in the research. This study was approved by the local ethics committee and all participants provided a signed informed consent.

We initially evaluated 198 patients, with 37 exclusions ( five were stroke mimics, two were diagnosed with a second stroke episode after admission into the study and 30 did not undergo a National Institutes of Health Stroke Scale (NIHSS) assessment upon admission). Thus, a total of 161 patients were analyzed (Figure 1). Individuals participating in the study had a mean age of $57 \pm 17.0$ years, $69 \%$ female. The majority of the cohort comprised individuals with low education (50\% with lower secondary education level and $19 \%$ illiterate); African-American ethnicity (84\%); and low-income (65\% $\leq 1$ minimum wage).

Previously-trained investigators applied the scales through structured interviews with the patient or family member, if the

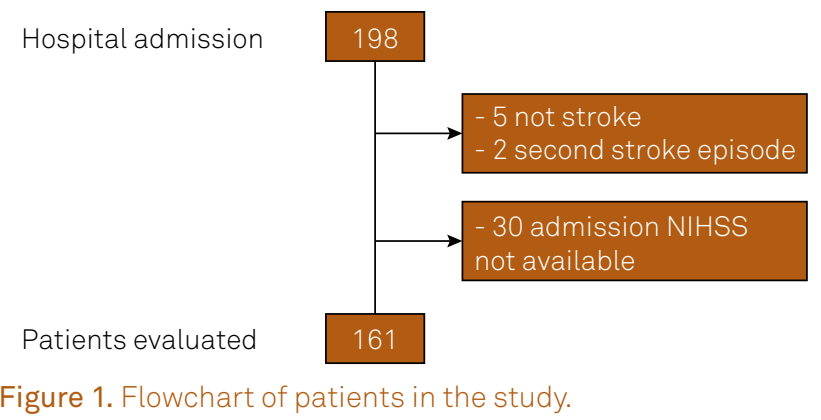

patient had aphasia or reduction in the level of consciousness, at the emergency, inpatient or stroke unit. Predictive validity was assessed by association between the FAI and NIHSS scores, sequentially applied in the period of hospital admission after the signs and symptoms of the acute event, from July 2011 to April 2013. To check inter-rater agreement of the Frenchay Activity Index, this scale was applied by two investigators, on the same day, but on different shifts, in a sample of consecutive patients admitted between October and December 2012.

\section{Tool description}

The FAI was used to assess IADL three and six months before the stroke. It consists of 15 items measuring complex activities in the categories of domestic activity, work/leisure and outdoor activity ${ }^{9}$. The FAI score is based on the frequency with which activities were performed in the previous three or six months, ranging from 0 (inactive) to 45 (very active) and can be classified as: $0-15=$ inactive; $16-30=$ moderately active, and 31-45 = very active ${ }^{12}$. The cutoff $\geq 18$ was used as a predictor of mild disability after stroke ${ }^{13}$.

Stroke severity was measured by the NIHSS, which establishes a quantitative evaluation of the severity of neurological disability by assessing the level of consciousness, language, neglect, visual field loss, extraocular movements, muscle strength, ataxia, dysarthria, and sensory loss. The higher the score, the more severe the stroke ${ }^{14}$. For the present study, we categorized the NIHSS scores into quartiles (0-1, 2-7, 8-13, 14-39).

The modified Barthel Index assesses the functional capacity of patients through quantification of daily activities. Its validity and inter-rater reliability have previously been established. The score ranges from 10 (completely dependent) to 50 (independent) and is classified as follows: $10=$ completely dependent; 11 to 30 = severely dependent; 31 to $45=$ moderately dependent; 46 to 49 = mildly dependent; and 50 = independent ${ }^{15}$.

\section{Statistical analysis}

Statistical Package for Social Sciences (SPSS) software version 17.0 was used for statistical analysis. Spearman's test was used to correlate scores from different scales. Analysis to measure interrater agreement was performed using the kappa coefficient on the total FAI score, considering a cutoff $\geq 18$, and the intraclass correlation coefficient for the analysis of continuous variables on the total score and the three FAI categories (domestic activity, work/leisure and outdoor activity), defining the degree of association as follows: poor association when $<0.20$; weak association from 0.21 to 0.40 ; moderate from 0.41 to 0.60 ; good from 0.61 to 0.80 and excellent when $\geq 0.80^{16}$. We used univariable ordinal regression to check which variables are associated with hospital admission NIHSS scores, selecting all variables with a possible association $(\mathrm{p}<0.2)$ with the NIHSS quartiles for inclusion in a model using ordinal logistic regression. The level of significance was set at $5 \%(\mathrm{p}<0.05)$. For the final ordinal logistic regression model, we tested the proportional odds assumption with a likelihood ratio test using STATA software. 


\section{RESULTS}

Table 1 shows the sociodemographic, clinical and functional data. We found a negative correlation between the FAI and stroke severity (NIHSS) $(r=-0.226, p=0.004)$ (Figure 2). The univariable ordinal regression showed that the variables: age, gender, education, diabetes, heart disease, atrial fibrillation, alcohol consumption and the FAI were possibly associated with admission NIHSS scores $(\mathrm{p}<0.2)$ (Table 2). Adjusting for all variables with a possible association with the NIHSS, the FAI remained a significant independent predictor of the NIHSS score (OR 0.93 per 1 point increase, $95 \%$ CI 0.87 to $0.99, \mathrm{p}=0.033$ ) (Table 3). The model was found to be appropriate through proportional odds testing $(\mathrm{p}=0.329)$.

Thirty-six patients were included in the inter-rater agreement analysis, with a mean age of $58.4 \pm 17.8$ years, $64 \%$ female. The majority of the population comprised married individuals (41\%), with low education (61\%) and African-American ethnicity $(70 \%)$. The inter-rater agreement, considering a cutoff $\geq 18$, was considered moderate to good, $\mathrm{k}=0.66$ ( 0.54 to 0.78 ), $\mathrm{p}<0.001$. However, correlation between continuous variables for the total score and for the three categories of the FAI was considered good and excellent (Table 4).

\section{DISCUSSION}

The FAI objectively evaluates instrumental activities prior to stroke, quantifying the level of activity and previous social participation of individuals. The present study assessed the reproducibility of FAI scores, previously translated into Portuguese ${ }^{13}$. Our results suggest good-to-excellent inter-rater reliability of the FAI as a measure of patient functionality prior to stroke.

Corroborating these findings, Post and Witte ${ }^{17}$ evaluated the FAI in 45 post-stroke patients in rehabilitation centers and demonstrated a good inter-rater reliability. Unlike these results, Green et al. ${ }^{18}$ analyzed the test-retest reliability of basic ADL and IADL scales in 22 patients, and demonstrated low reliability for the IADL scale, assessed by the FAI and the Nottingham extended ADL scale. Similar to these findings, Piercy et al. ${ }^{19}$ evaluated the inter-rater reliability of the FAI and found that none of the items had an excellent concordance. This divergence may have occurred because individuals in the latter studies were evaluated one year after stroke and the second inter-rater assessment occurred seven to 20 days after the first evaluation. Thus, the results could have been influenced by recall bias or health changes occurring during the period between tests ${ }^{20}$.

The present study demonstrated a significant correlation, although weak, using Spearman's test, between the FAI and NIHSS scores in the acute phase, possibly due to the additional association of other variables with the outcome NIHSS scores. Thus, using ordinal logistic regression, we found that
Table 1. Description of sociodemographic, clinical and functional variables of the studied population.

\begin{tabular}{|c|c|}
\hline Variables & Patients $(n=161)$ \\
\hline Age mean (SD) & $57.3(17.0)$ \\
\hline Gender: Female n (\%) & $111(68.9)$ \\
\hline \multicolumn{2}{|l|}{ Ethnicity n (\%) } \\
\hline African-American & $135(83.8)$ \\
\hline White & $17(10.6)$ \\
\hline Others & $9(5.6)$ \\
\hline \multicolumn{2}{|l|}{ Education n(\%) } \\
\hline Illiterate & $31(19.3)$ \\
\hline Elementary School & $80(49.7)$ \\
\hline High School & $40(24.8)$ \\
\hline Others & $10(6.2)$ \\
\hline Income $\leq 1$ minimum wage $\mathrm{n}(\%)$ & $105(65.2)$ \\
\hline Ischemic stroke n (\%) & $98(60.9)$ \\
\hline NHISS score median (IQ) & $8(2-15)$ \\
\hline \multicolumn{2}{|l|}{ Comorbidities n (\%) } \\
\hline Hypertension & $129(80.1)$ \\
\hline Diabetes & $27(16.8)$ \\
\hline Heart disease & $30(18.6)$ \\
\hline Atrial Fibrillation & $12(7.5)$ \\
\hline Depression & $3(1.9)$ \\
\hline Interval of time from stroke (days) median (IQ) & $6(4-12)$ \\
\hline \multicolumn{2}{|l|}{ Previous lifestyle n (\%) } \\
\hline Smoker or ex-smoker & $63(39.2)$ \\
\hline Alcohol consumption & $75(46.6)$ \\
\hline Physical exercise & $26(16.1)$ \\
\hline Reading & $37(23.0)$ \\
\hline FAl prior median & $21(16-24)$ \\
\hline Admission MBI median (IQ) & $32(23-45)$ \\
\hline
\end{tabular}

FAl: Frenchay activity index; MBI: Modified Barthel Index; NIHSS: National Institutes of Health stroke scale; SD: standard deviation; IQ: range interquartile (Q1/Q3).

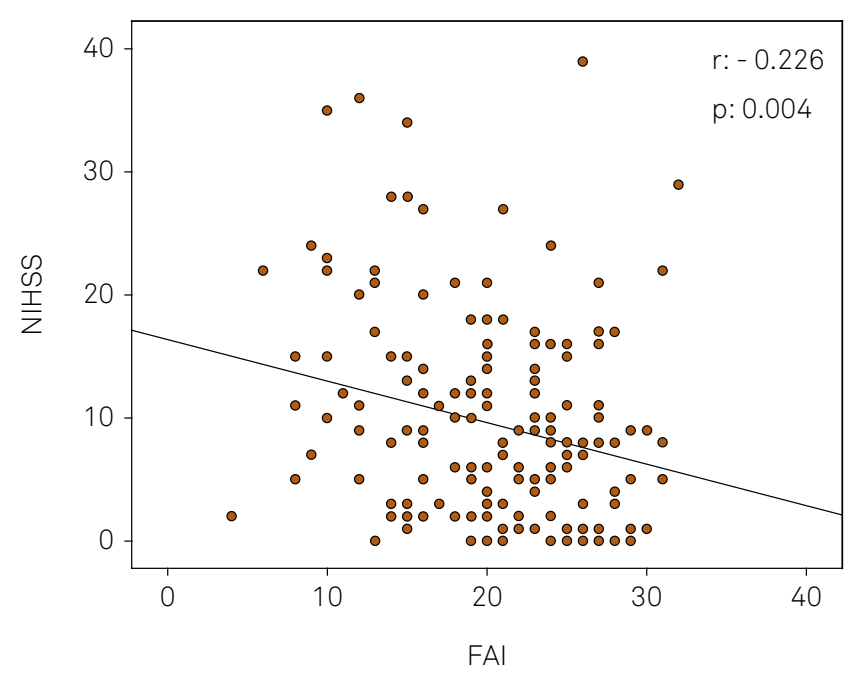

Figure 2. Correlation between Frenchay Activity Index (FAI) and stroke severity assessed by the National Institutes of Health Stroke Scale (NIHSS). 
Table 2. Variables associated with hospital admission NIHSS in 161 patients with stroke, using univariable ordinal regression.

\begin{tabular}{|lccc}
\hline Variables & $\begin{array}{c}\text { Odds } \\
\text { ratio }\end{array}$ & $95 \% \mathrm{Cl}$ & $\mathrm{p}$ \\
\hline Age & 1.02 & $1.01-1.04$ & 0.002 \\
\hline Gender & 0.54 & $0.27-1.04$ & 0.067 \\
\hline $\begin{array}{l}\text { Education (for increasing } \\
\text { categories of higher education) }\end{array}$ & 0.52 & $0.34-0.79$ & 0.002 \\
\hline Income & 1.01 & $0.62-1.64$ & 0.962 \\
\hline Comorbidities & & & \\
\hline$\quad$ Hypertension & 1.29 & $0.62-2.69$ & 0.493 \\
\hline$\quad$ Diabetes & 3.43 & $1.19-6.89$ & 0.019 \\
\hline Heart disease & 1.96 & $0.90-5.26$ & 0.083 \\
\hline Atrial Fibrillation & 2.47 & $0.67-9.43$ & 0.170 \\
\hline$\quad$ Obesity & 2.92 & $0.86-10.75$ & 0.090 \\
\hline Interval of time from stroke (days) & 0.97 & $0.91-1.02$ & 0.278 \\
\hline Previous lifestyle & & & \\
\hline \multicolumn{1}{l}{ Smoker or ex-smoker } & 1.75 & $0.65-4.79$ & 0.266 \\
\hline Alcohol consumption & 1.69 & $0.92-3.14$ & 0.090 \\
\hline FAl (for every increase in 1 point) & 0.91 & $0.86-0.96$ & 0.002 \\
\hline
\end{tabular}

FAl: Frenchay activity index; NIHSS: National Institutes of Health stroke scale; Cl: confidence interval.

Table 3. Association between pre-stroke instrumental activities (Frenchay activity index) and hospital admission NIHSS in 161 patients with stroke, using ordinal logistic regression.

\begin{tabular}{lccccc}
\hline Variable & Unadjusted & & Adjusted & & Pd \\
\cline { 2 - 2 } & OR; $95 \% \mathrm{Cl}$ & & OR; $95 \% \mathrm{Cl}$ & \\
\hline $\begin{array}{l}\text { FAl* (for every } \\
\text { increase in 1 point) }\end{array}$ & $0.91 ; 0.86-0.96$ & & $0.93 ; 0.87-0.99$ & 0.033 \\
\hline
\end{tabular}

FAl: Frenchay activity index; NIHSS: National Institutes of Health STROKE SCALE;OR: odds ratio; Cl: confidence interval. *Adjusting for all variables with possible association ( $p<0.2$ ) with NIHSS (diabetes mellitus, heart disease, atrial fibrillation, obesity, alcohol consumption, age, gender, education).

Table 4. Analysis of intra-class correlation between the first and second evaluator for continuous scores of FAl.

\begin{tabular}{lccc}
\hline FAl score & ICC & $95 \%$ ic & P \\
\hline Total & 0.827 & $0.69-0.91$ & $<0.001$ \\
Domestic & 0.875 & $0.77-0.93$ & $<0.001$ \\
Work/leisure & 0.735 & $0.54-0.86$ & $<0.001$ \\
Outdoor activities & 0.752 & $0.57-0.87$ & $<0.001$ \\
\hline
\end{tabular}

FAl: Frenchay Activity Index; Cl: confidence interval; Analysis performed using intraclass correlation coefficient (ICC).

the previous lifestyle has a significant association with the hospital admission stroke severity, indicating an independent predictive validity of the FAI to post-stroke status. As in previous research, this study demonstrated a negative correlation between the stroke severity and previous IADL, assessed by the $\mathrm{FAI}^{13}$. Some studies suggest that physical activity, besides reducing stroke risk ${ }^{21}$, promotes increased blood flow and decreased neurological injury during brain ischemia ${ }^{5}$.
The Nottingham Extended ADL scale and the FAI have been used as reliable, valid and responsive tools for predicting functional outcome in stroke patients ${ }^{22}$. One study compared the responsiveness and validity of the two IADL scales and demonstrated that, regarding concurrent validity, they are comparable, although the Nottingham Extended ADL scale showed greater sensitivity. Their use as a functional predictor in the acute phase after stroke, however, is inadequate $^{22,23}$. Neverthless, because the FAI assesses the frequency with which instrumental activities are conducted in the recent past, it may be used in the acute phase as a predictor of stroke severity or functional outcome after stroke'.

In a validation study of the FAI developed in Portugal, which analyzed a sample of patients with low education nine months after stroke, researchers reported that the FAI could be difficult to interpret and gave ambiguous results because patients were unfamiliar with several activities prior to stroke event. They suggested that the score, which is originally based on the frequency of activities, be altered to one that measures the individual's perception about the ability/inability to perform these tasks instead. In the present study, conducted in a heterogeneous post-stroke population, we found the scale easy to use in its original form, used solely to identify the performance of individuals in instrumental activities prior to stroke, through the frequency with which the tasks were performed, with no possibility of ambiguous responses ${ }^{24}$.

The FAI has been used in studies to assess instrumental activities prior to stroke, as a functional predictor or for evaluation at the end of rehabilitation, applied as an outcome measure, ${ }^{9,25}$. Other studies have validated the use of the scale in chronic diseases ${ }^{26}$ and different populations ${ }^{27,28}$. In clinical practice, assessment of functional pre-stroke performance assists in setting specific goals early in the process of rehabilitation ${ }^{29}$. A moderate-to-excellent rate of inter-rater agreement in the FAI application was demonstrated in this study, making it a useful scale with this objective.

Cognition and depression are variables identified in the literature that may influence IADL. However, in this study, these variables were collected from medical records, which limits their reliability as concomitant predictors. Thus, further studies using validated scales to assess the influence of cognition on functional capacity are needed. The FAI was assessed as a functional predictor in the acute phase of stroke; thus, additional experiments are needed to measure the applicability of this index in other populations and as an outcome measure.

In conclusion, we demonstrated that the FAI is a useful tool to assess instrumental activities prior to stroke, with good inter-rater reliability and predictive validity.

\section{Acknowledgments}

The authors thank Camila Gonçalves, Flávia Laís Silva, Layse Tatiane, Mayara Almeida and Tassiana Mendel, for their collaboration in data collection for this research. 


\section{References}

1. Adamson J, Beswick A, Ebrahim S. Is stroke the most common cause of disability? J Stroke Cerebrovasc Dis. 2004;13(4):171-7. https://doi.org/10.1016/j.jstrokecerebrovasdis.2004.06.003

2. Ferri CP, Schoenborn C, Kalra L, Acosta D, Guerra M, Huang Y et al. Prevalence of stroke and related burden among older people living in Latin America, India and China.J Neurol Neurosurg Psychiatry. 2011;82(10):1074-82. https://doi.org/10.1136/jnnp.2010.234153

3. Thijs VN, Lansberg MG, Beaulieu C, Marks MP, Moseley ME, Albers GW. Is early ischemic lesion volume on diffusionweighted imaging an independent predictor of stroke outcome? A multivariable analysis. Stroke. 2000;31(11):2597-602. https://doi.org/10.1161/01.STR.31.11.2597

4. Weimar C, Ziegler A, König IR, Diener HC. Predicting functional outcome and survival after acute ischemic stroke. J Neurol. 2002;249(7):888-95. https://doi.org/10.1007/s00415-002-0755-8

5. Endres M, Gertz K, Lindauer U, Katchanov J, Schultze J, Schröck H et al. Mechanisms of stroke protection by physical activity. Ann Neurol. 2003;54(5):582-90. https://doi.org/10.1002/ana.10722

6. Bragoni M, Caltagirone C, Troisi E, Matteis M, Vernieri F, Silvestrini M. Correlation of cerebral hemodynamic changes during mental activity and recovery after stroke. Neurology. 2000;55(1):35-40. https://doi.org/10.1212/WNL.55.1.35

7. Bode RK, Rychlik K, Heinemann AW, Lovell L, Modla L. Reconceptualizing poststroke activity level using the Frenchay Activities Index. Top Stroke Rehabil. 2003;9(4):82-91. https://doi.org/10.1310/RCWL-75JJ-JREW-FVQT

8. Schuling J, de Haan R, Limburg M, Groenier KH. The Frenchay Activities Index. Assessment of functional status in stroke patients. Stroke. 1993;24(8):1173-7. https://doi.org/10.1161/01.STR.24.8.1173

9. Wade DT, Legh-Smith J, Langton Hewer R. Social activities after stroke: measurement and natural history using the Frenchay Activities Index. Int Rehabil Med. 1985;7(4):176-81. https://doi.org/10.3109/03790798509165991

10. Kulzer AM. Associação entre atividades físicas, cognitivas e sociais e o grau de recuperação funcional após acidente vascular cerebral [dissertation]. Universidade Federal do Rio Grande do Sul, Porto Alegre, 2006.

11. World Health Organization. WHO STEPS Stroke manual: the WHO STEP wise approach to stroke surveillance/ Non communicable diseases and mental health. Geneva: World Health Organization; 2005.

12. Anderson CS, Jamrozik KD, Broadhurst RJ, Stewart-Wynne EG. Predicting survival for 1 year among different subtypes of stroke. Results from the Perth Community Stroke Study. Stroke. 1994;25(10):1935-44. https://doi.org/10.1161/01.STR.25.10.1935

13. Külzer AM, Scolari CC, Gus M. Relationship between usual physical, cognitive and social activities and functional recovery at hospital discharge after acute stroke. J Rehabil Med. 2008;40(3):195-9. https://doi.org/10.2340/16501977-0149

14. Brott T, Adams HP Jr, Olinger CP, Marler JR, Barsan WG, Biller J et al. Measurements of acute cerebral infarction: a clinical examination scale. Stroke. 1989;20(7):864-70. https://doi.org/10.1161/01.STR.20.7.864

15. Cincura C, Pontes-Neto OM, Neville IS, Mendes HF, Menezes DF, Mariano DC et al. Validation of the National Institutes of Health
Stroke Scale, modified Rankin Scale and Barthel Index in Brazil: the role of cultural adaptation and structured interviewing. Cerebrovasc Dis. 2009;27(2):119-22. https://doi.org/10.1159/000177918

16. Brennan P, Silman A. Statistical methods for assessing observer variability in clinical measures. BMJ. 1992;304(6840):1491-4. https://doi.org/10.1136/bmj.304.6840.1491

17. Post MW, Witte LP. Good inter-rater reliability of the Frenchay: activities Index in stroke patients. Clin Rehabil. 2003;17(5):548-52. https://doi.org/10.1191/0269215503cr648oa

18. Green J, Forster A, Young J. A test-retest reliability study of the Barthel Index, the Rivermead Mobility Index, the Nottingham Extended Activities of Daily Living Scale and the Frenchay Activities Index in stroke patients. Disabil Rehabil. 2001;23(15):670-6. https://doi.org/10.1080/09638280110045382 PMID:11720117

19. Piercy M, Carter J, Mant J, Wade DT. Inter-rater reliability of the Frenchay Activities Index in patients with stroke and their carers. Clin Rehabilit. 2000;14:433-40. https://doi.org/10 10.1191/0269215500cr327oa.

20. Imam B, Miller WC. Reliability and validity of scores of a Chinese version of the Frenchay Activities Index. Arch Phys Med Rehabil. 2012;93(3):520-6. https://doi.org/10.1016/j.apmr.2011.07.197

21. Krarup LH, Truelsen T, Pedersen A, Lerke H, Lindahl M, Hansen L et al. Level of physical activity in the week preceding an ischemic stroke. Cerebrovasc Dis. 2007;24(2-3):296-300. https://doi.org/10.1159/000105683

22. Wu CY, Chuang LL, Lin KC, Horng YS. Responsiveness and validity of two outcome measures of instrumental activities of daily living in stroke survivors receiving rehabilitative therapies. Clin Rehabil. 2011;25(2):175-83. https://doi.org/10.1177/0269215510385482

23. Hsueh IP, Huang SL, Chen MH, Jush SD, Hsieh CL. Evaluation of stroke patients with the extended activities of daily living scale in Taiwan. Disabil Rehabil. 2000;22(11):495-500. https://doi.org/10.1080/096382800413989

24. Martins T, Ribeiro J, Garret C. Estudo de adaptação e validação do Frenchay Activities Index FAl numa amostra de doentes com baixa escolaridade afetados por acidente vascular cerebral. Arq Med. 2003;17:88-91.

25. Lin KC, Chen HF, Wu CY. Multidimensional rash validation of the Frenchay Activities Index in stroke patients receiving rehabilitation. J Rehabil Med. 2012;44(1):58-64. https://doi.org/10.2340/16501977-0911

26. Ytterberg C, Johansson S, Andersson M, Widén Holmavist L, von Koch L. Variations in functioning and disability in multiple sclerosis: a two-year prospective study. J Neurol. 2008;255(7):967-73. https://doi.org/10.1007/s00415-008-0767-0

27. Chang- Wan Han, Yuki Yajima et al. Construct validity of the Frenchay Activities Index for community-dwelling elderly in Japan. Tohoku J Exp Med. 2006;201(2):99-107.

28. Turnbull JC, Kersten P, Habib M, McLellan L, Mullee MA, George S. Validation of the Frenchay Activities Index in a general population aged 16 years and older. Arch Phys Med Rehabil. 2000;81(8):1034-8. https://doi.org/10.1053/apmr.2000.7162

29. Dobkin BH. Clinical practice. Rehabilitation after stroke. N Engl J Med. 2005;352(16):1677-84. https://doi.org/10.1056/NEJMcp043511 